\title{
Rainfall in Bangladesh: Is Rainwater Harvesting a Sustainable Approach for Governing Rainwater?
}

\author{
M. Rafiqul Islam ${ }^{1}$
}

\begin{abstract}
Global environmental change affects the intensity and frequency of rainfall that increases the necessity for sustainable management of rainwater. It is more important for rain intensive country like Bangladesh otherwise it creates further problems like water logging, flood, soil erosion, and water borne diseases. Based on the survey of 80 rainwater harvesters in the Coastal Bangladesh in 2017, this paper evaluates whether rainwater harvesting is sustainable approach to govern rainwater or not by using social and ecological performance measures of Social Ecological System (SES) of Elinor Ostrom. This study found that rainwater harvesting does not affect environment, it is an acceptable approach in family and society, help to develop biodiversity condition, create resilience to climate change impact, improve equitable access to water, efficient use of rainwater, improve women performance regarding water supply to the family, contribute in achieving sustainable development goal, and do not overharvest of rainwater that could create environmental problem. Beyond these measures, it needs rainwater harvesting controlling mechanism like formal operation rule or policy to avoid overharvesting and ensure more sustainability in governing rainwater.
\end{abstract}

Keywords: Accountability; Biodiversity; Efficiency; Resilience; Equity; Global environmental change; Rainwater harvesting; Sustainable approach; Sustainable development goals; Sustainable management of rainwater

\section{Introduction}

Water resource is one of the main pillars of sustainable development that acknowledged in the United Nations Conference on Sustainable Development at Rio de Janeiro in 1992. The Sustainable Development Goals of the United Nations has given importance on sustainable management of water resources (Goal 6) and ensure available safe water for all. Therefore, the present study focuses on a sustainable approach to govern rainwater by integrating social and ecological performance measures in Southwest Bangladesh. It is expected that this study will contribute to the development of sustainable water resources management concepts and understand the phenomena of sustainable approach for governing rainwater in terms of social and ecological performance measures in rain intensive country like Bangladesh.

Bangladesh is well known for climate-induced extreme events such as drought, flood, cyclone, storm surges, river bank erosion, and salinity intrusion. Rainfall is one of the meteorological variables that play a very important role in the hydrological cycle and on these climate-induced extreme events (Islam and Hasan, 2012). Climate change has a profound impact on intensity and frequency of rainfall all over the world and global warming will intensify it (Allan and Soden, 2008; Wasimi, 2009). Alexander et al. (2006) argued that the intensity of rainfall is increasing worldwide that lead to the enhancement of heavy rainfall indices. Goswami et al. (2006) found that intensity and frequency of rainfall have been increasing over Central India. They analyzed the data from 1951 to 
2002. This extension of rainfall in terms of frequency and intensity has a large impact on Bangladesh as the country is one of the most rain intense countries in the world. However, in the northwestern part of the country, drought is a common phenomenon (Shahid, 2008; Shahid and Behrawan, 2008). The country has experienced a number of dry and wet periods in the last fifty years (Shahid, 2010). Global warming has already started to affect the rainfall patterns and facilitate frequent extreme events such as droughts, floods, and heavy rainfall all over the world (Briffa et al. 2009; Schmidli and Frei, 2005; Zhang et al. 2009) and will widen the gap between wet season and dry season. It indicated that more and less rainfall will take place in wet season and dry season respectively. This increasing trend of erratic rainfall affects the region's drinking water supply, agricultural production, and environment. Moreover, water demand will increase due to population growth, intensification of agricultural production, urbanization, and economic development (Ismail, 2016). Both of these issues create challenges for the Government of Bangladesh, donor agencies, and non-government organization to manage the rainwater, mitigate the effect, and make the socioeconomic development sustainable in the region. In this context, it needs to find out the way to sustainable governance of rainwater in Bangladesh. Otherwise, it will hamper the socioeconomic and environment developmental effort.

Rainwater harvesting is the collection, storing, and utilizing runoff from roofs or ground surfaces for productive use in domestic water supply, agricultural use, and environmental management (Anderson and Burton, 2009; Falkenmark et al. 2001; Liniger et al. 2011; Niggi, 2003; Worm and Hatum, 2006). It has been using for centuries over the globe. Rainwater can be used for different purposes like irrigation, drinking, washing, and cooking (Worm and Hatum, 2006). Generally, there are three different kinds of rainwater harvesting systems (RHS) such as rooftop catchment system, runoff catchment system, and in-situ catchment system (Pachpute et al. 2009). Studer and Linger (2013) argued that there are three main components of rainwater harvesting: (i) catchment or collection area where rainfall is the runoff and harvested. It can be rooftop, pavement, cultivated or uncultivated land, compacted surfaces, open rangelands, and rocky areas; (ii) Conveyance system where runoff is carried out via gutters, and pipes; (iii) Storage facility where collected rainwater is stored until it is used. Oweis et al. (2012) found that collected rainwater can be stored above the ground (e.g. jars, soil or plastic tank, ponds or reservoirs) or below the ground (e.g. cisterns) as groundwater. When considering the rainwater harvesting as an alternative or supplement source of water it needs to consider the sustainable issue for applying this system.

There are not many studies regarding the factors of determining the sustainability of RHS. Pachpute et al. (2009) found that RHS has been facing some constraints such as lack of policy support and budget, lack of knowledge and skills that can facilitate institutions, and inadequate scientific and socioeconomic knowledge. These constraints are affecting the sustainable aspect of rainwater harvesting. Ostrom (2009) indicated that outcome of a natural resources (e.g. rainwater) from the interaction of resource systems, resource units, users, governance systems in large social, economic, and political settings can be measured in terms of social performance indicators such as accountability, efficiency, equity, conflict etc. and ecological performance measures such as overharvested, biodiversity, sustainability etc. Efficiency and effectiveness use of 
collected rainwater rely on skills, investment capacities, and technical knowledge of the user. The climatic variability at regional scale increases the frequency of extreme events (e.g. prolonged drought and dry spell, intensity of rainfall etc.) which lead to affect the temporal and spatial availability of rainfall/runoff (Mizyed, 2008; Trisan and Polcher, 2008) Rockstrôm et al. (2007) found that it is needed to adopt the small catchment management approach for upgrading rainfed agriculture as well as contribute to the environmental conservation by reducing water withdrawal from groundwater source.

The sustainable approach for governing rainwater under various biophysical and socioeconomic positions is a key for large scale socioeconomic and environmental development in coastal Bangladesh. Sustainable approach signifies that the "present harvesting, use and consumption of natural resources through rainwater harvesting system can be continued into the future for optimal livelihoods generation" (Pachpute et al. 2009: 2817). Pachpute et al. (2009) argued that there are three main attributes to determine whether RHS is sustainable or not. Such attributes are (i) dependable water supply and production potential; (ii) minimum negative impact on natural resources and environment; and (iii) effective water use. This study used the social performance measures and ecological performance measures of Social and Ecological System (SES) framework of Elinor Ostrom to determine whether rainwater harvesting is a sustainable approach to govern rainwater or not.

\section{Materials and Methods}

In order to assess the sustainable approach of rainwater management, it needs quality information. For collecting quality information, it needs to use specific tools and technique. This chapter explores what information is collected, how, and what methods applied to collect and analyze collected information. It includes social performance measures information in terms of efficient use of rainwater, equity, acceptance of rainwater harvesting in family and society and ecological performance measures regarding overharvesting, biodiversity, resilience, and sustainability. Figure 1 shows the analytical framework of this study.

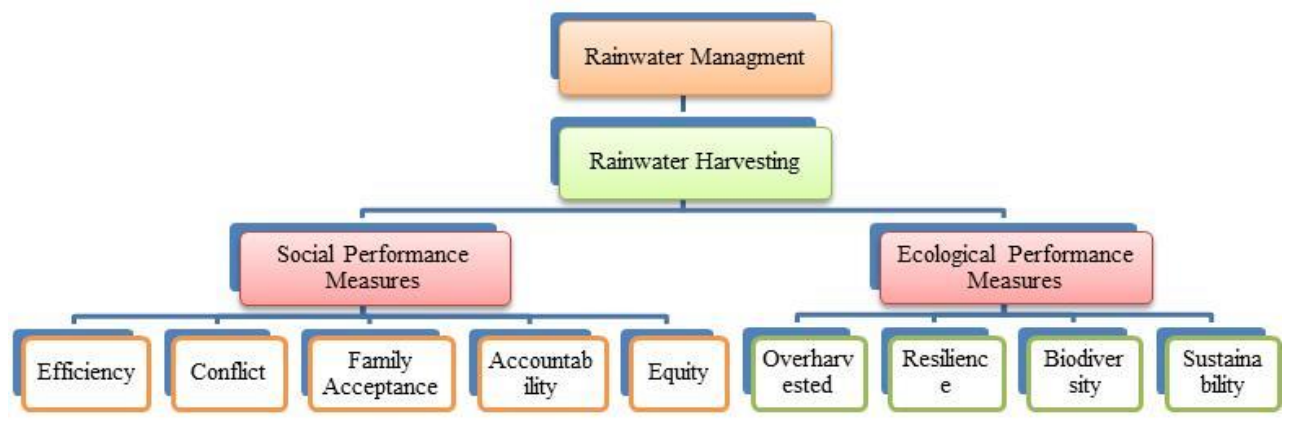

Figure 1: Analytical framework for measuring social and ecological performance of rainwater harvesting (Adapted from Ostrom, 2005, 2007, 2009) 
Information for checking the sustainable approach of rainwater harvesting was collected from a coastal community of Bangladesh through the participatory approach. Participatory Rural Appraisal (PRA) is "a family of approaches and methods to enable rural people to share, enhances, and analyzes their knowledge of life and conditions, to plan and act" (Chambers, 1994:953). PRA methods applied in this study because its main objective is to empower local people and produce sustainable actions and institutions as long term outcomes (Chambers, 1994). Chambers (1994) argued that PRA not only helps to discover the profound knowledge of villagers but also their creative abilities to sustainable management of natural resources. Its different tools such as participatory social mapping, semi-structured interview, key informants, transect walk, short standard schedules, and group discussion with local people used to collect information from the study site.

Focus group discussions (FGD) (10-15 participants) were held in three different places in the study site. FGDs were held on the basis of open-ended semi-structured interview questions. FGD commenced with a brief explanation of the research objective and expectations from the participants in the FGD. They were asked to identify the outcome of rainwater harvesting in terms of efficiency, social and family acceptance, equity, biodiversity, overharvesting, accountability, and environmental impact. Participants drew connections between the role of government and NGOs and the application of rainwater harvesting system. Moreover, they suggested that if they would get benefit from either of these in terms of finance, technical knowledge, and training, this system of rainwater management would be more effective, efficient, and sustainable as well as could address their water crises problem.

Besides FGD, the author also used key informant (participatory social mapping used to select key informant), transect walk with local people in the study site for discussing, listening, observing, and asking about rainwater harvesting, and short standard schedule tools to collect information on rainwater harvesting as rainwater management tools and its performance measure in terms of social and ecological performance measures.

\section{Study Location}

As I have mentioned that the paper focuses on one coastal community of Bangladesh. One coastal community of Bagerhat District was selected as the study site because they are a good representative of coastal communities in terms of climate change vulnerability, socioeconomic position, and dependability on natural resources. More importantly, they have been practicing rainwater harvesting for a long time for addressing their water crises problem. The area is attributed by poverty striven people who are more than 90 percent depend on natural resources and agriculture for their livelihood. The community belongs to Mongla Upazila (Upazila: subunit of a district) located at the Low Elevation Coastal Zone (LECZ) of Bangladesh. LECZ can be defined as an area with a coastline up to ten-meter sea level elevation (McGranahan et al. 2007). The name of the community is Chilla under Mongla Upazila of Bagerhat District in Bangladesh. Coastal areas of Bangladesh suffer with different kind of climatic and non-climatic extreme events such as salinity intrusion, storm surge, cyclone, sea level rise, floods, erratic rainfall, drought, and endemic poverty (Huq et al. 2015). Figure 2 shows 
the study site in Bangladesh.
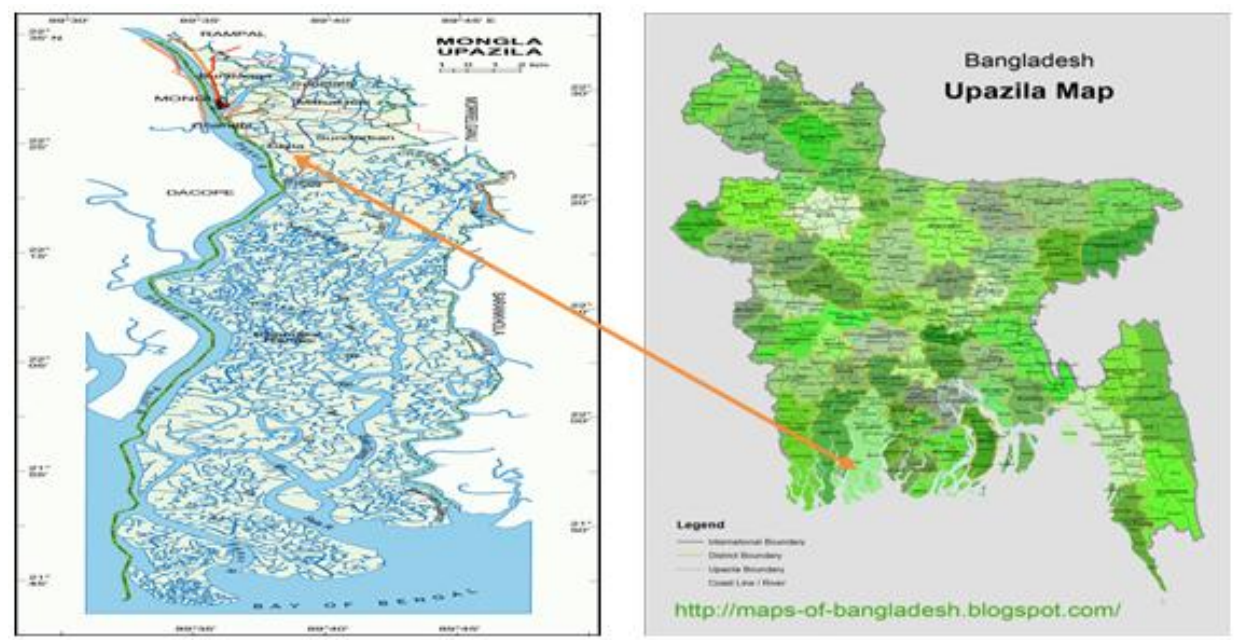

Figure 2: Location of the study site

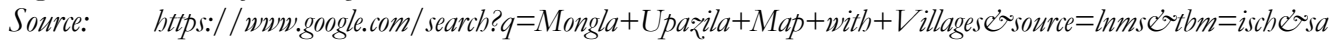

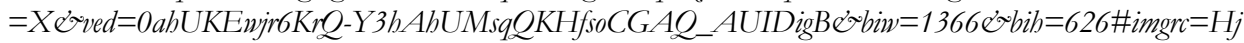
L8RDZzc4umjM: and bttp://3.bp.blogspot.com/_Xh4MstvdVIw/TAll8Z6iRYI/AAAAAAAAAIM /Kz_OGyuch_ko/s1600/Upazila\%2BMap\%2Bof\%2BBangladesh.gif

\section{Social and Ecological Performance Measures}

The research primarily centered on two performance measures of Elinor Ostrom's SES framework. The first major performance measure is social and the second is ecological. It is the outcome of an ecological resource through an interaction process of resource system, resource unit, users, and governance system in large socioeconomic and political settings.

\subsection{Social Performance Measures}

\subsubsection{Equity}

Equitable access to water is very important and remains one of the major challenges for sustainable development. Generally, water management programs by government offered benefits to rich people in terms of access to water by providing finance or water harvesting materials or digging large and deep freshwater pond under the control of these rich people. As development funds are going to rich people poor people are more suffered and deprive their right in terms of access to water. Moreover, it increases the inequity in society. But rainwater harvesting system makes women and poor people better by increasing access to water that makes the positive contribution to their livelihood. Some of the participatory projects found that rainwater harvesting helps to maintain equity in terms of access to water and ensures that almost everyone benefitted from rainwater. According to the household survey, 89 percent of respondents replied positively in terms of access to water with rainwater harvesting. They also mentioned that during monsoon their access to water improves significantly due to their rainwater 
harvesting facility. Although their harvesting facility is not well equipped like rich people but it helps in access to water. If they don't have it they will face the same problem like summer when they don't have access to water because of lack of financial capacity to buy water from either water trader or water company or lack of political power.

During summer, the difference between rich and poor people in terms of access to water is very high but it is low in monsoon. The reason behind this is rainwater harvesting and financial capacity. There are some factors working behind this aspect: (i) rich people have the capacity to buy water from either water trader or water company; (ii) they have a deep and large freshwater pond; (iii) getting benefit from government and nongovernment organization for accessing water. However, the coastal community gets neither of those benefits as they are poor and does not have political and monetary power so that it is not possible to get access to water like rich people. In this context, rainwater harvesting can contribute to equitable access to water in the study site.

\subsubsection{Efficiency}

Rainwater is natural resources and most of the household at Chila capture, store, and use rainwater for various purposes such as cooking, bathing, washing, drinking, and other domestic purposes. In the study group, $93.75 \%$ of households collect and use rainwater but everyone can't use collected rainwater over the whole year because of a storage problem. They also can't use rainwater for all purposes due to the same problem. They use collected rainwater for a different purpose in different seasons. For instance, during the dry season ${ }^{1}$, they use rainwater for drinking purpose only because rainfall does not take place frequently. However, during monsoon ${ }^{2}$, it uses for all purposes from drinking to bathing as the rainfall takes place almost every day. If they don't capture rainwater like other regions (e.g. Dhaka) it would runoff to canal, rivers, and pond where water is saline which might cause to increase the volume of saline water. In this circumstance, rainwater harvesting ensures efficient use of the natural resource (e.g. rainwater) and addresses their water crises problem.

\subsubsection{Accountability}

Accountability is strongly connected to two aspects in this study: (i) to the women's performance in supplying and managing water for her family as they are primarily responsible in managing water for the family; (ii) rainwater harvesting increases in access to water for women that make the positive contribution to their performance. Figure 3 shows the relation among rainwater harvesting, access to water and women performance. However, in coastal Bangladesh, women are socioeconomically vulnerable and climate change impact has been deteriorating their position with creating more challenges in terms of supplying water to the family but rainwater harvesting helps them to perform their duty effectively. They can supply sufficient water to the family during the rainy season as there is sufficient rainfall. They can also store rainwater for using beyond the monsoon.

\footnotetext{
${ }^{1}$ Dry season $=$ summer. It indicates the period from March to June

${ }^{2}$ Monsoon $=$ wet season= rainy season. It indicates the period from June to October
} 


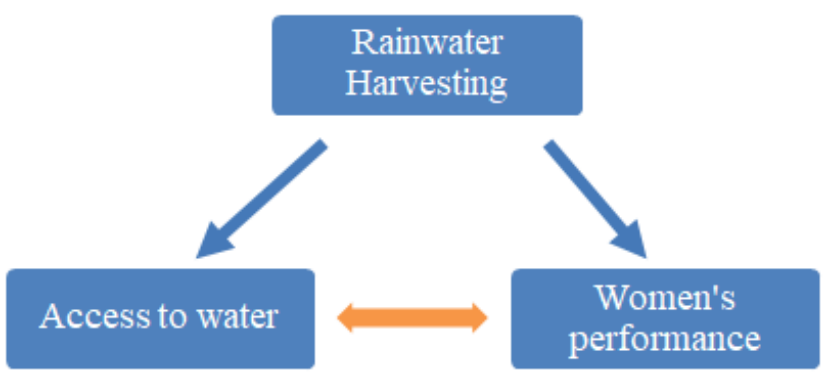

Figure 3: Relation between rainwater harvesting and accountability in terms of access to water for women and their performance

In the coastal zone of Bangladesh, women and girls are responsible for supplying water to the family. They are always exposing to the risk of water crises for their family in terms of handling pressure from collecting, using, and storing water for future use. They need to manage water for their family. If they can't manage, it could bring a devastating impact on their family. Rainwater harvesting can improve the access to water for women and girls that ensure their accountability to the family regarding the supplying water to the family. According to the survey, all of them informed that their water supply improves with rainwater harvesting. They also informed that if they have enough storage capacity to store rainwater they could collect enough rainwater for the whole year and they could perform their duty more effectively.

\subsubsection{Conflict}

Rainwater harvesting system uses to collect rainwater, store for future, and for present use. The collected water uses for different purposes like dishwashing, cooking, drinking, bathing, and other domestic purposes so that everyone tries to get benefit from rainwater. In this context, social coherence is very important for maintaining the system. This study found that social class and other norms do not affect rainwater harvesting as the system has been using from generation to generation in the area. Regarding this aspect, there are some factors are important to consider such as different people use the collected water for different purposes, collect a different volume of water, and use the different technique to collect water so that it can arise conflict among them. If it causes conflict among them the system might not be useful and effective for them.

During the study, the researcher asked the participants are they face any social conflict regarding rainwater harvesting or are they get complain against the system. As per response of the questions, they informed that nobody complaints against the system even they cooperate with each other to effective and efficient use of collected rainwater. They also informed that they share their skills and knowledge to improve their rainwater collection technique because the endurance of quality of collected water depends on the collection technique and storing methods.

\subsubsection{Family Acceptance}

Family acceptance is another major attribute to check the sustainability of the system as the system is using in the household and for the family member. If the family member does not support the system, the system is vulnerable in that specific family so 
that it is very important to get family support to operate the system and maintain the system. This support can be in terms of rainwater collection, cleaning the storage tank and other materials, installing the infrastructure etc. According to the field study of this research, the entire participants informed that they are getting support from the family member. For instance, the person is not in the home who generally operate the system during rainfall but another person is in the home. The person who is in the home will collect the rainwater. Moreover, the adult person can't go inside of the storage tank so that a young member of the family helps to clean the storage tank.

\subsection{Ecological Performance Measures \\ 4.2.1 Overharvested}

In light of increasing water crises problem, particularly in the climate change affected coastal region, it is possible to overexploit the rainwater to address the problem. If all rainwater is collected then it will create problems. Rainwater runoff washed the pollutants and wastages from inland to pond to river to oceans. In the ocean, it is dissolved naturally. If all rainwater is collected then all pollutants and wastages will remain in the same position (e.g. inland, agriculture field, pond, local freshwater bodies etc.) that will create further problems. Moreover, rainwater is a major source of recharging the groundwater. Collection of all rainwater will hamper the recharge of groundwater and lower the groundwater level that will create problem in access to water level by wells. Moreover, ultimately it will create problem for the local ecosystem.

In Bangladesh, there is no policy regarding rainwater harvesting. In the study area, people can't overexploit the rainwater due to lack of financial capacity, and technical know-how. Even they can't collect enough rainwater for their own purpose due to the same constraint. But as climate change impact increases the intensity of water crises problem will be increased so that people will try to manage their water crises with overexploitation of resource (e.g. rainwater) which is available to them. Generally, people try to solve their problem with the resources which are available and easily reachable to them. For example, people have been using groundwater as the main source of water as it is available, cheap, and easily reachable. This practice increased significantly in the last 50 years that lead to overexploitation. This overexploitation endangers the sustainability of aquifer. In the same way, there is a possibility to overexploit the rainwater in near future to address the water crises problem so that it is better to prepare and apply the proper policy to monitor the rainwater harvesting to stop overexploitation of rainwater.

\subsubsection{Biodiversity}

Water is very important ingredient for living beings and nothing can exist without water. Water is a prerequisite for sustaining both inland and marine biodiversity. Accessibility and ingredients of water govern and control the efficiency of biodiversity conservation. It is a matter of fact but true that policymaker, academics, and other concern bodies face serious challenges to protect biodiversity. Biodiversity suffers when water becomes scarce. For example, during dry season a number of wild animals migrate from water scarce areas to another area where water is available. In this situation, hunters use water as a trap to hunt the animals. Proper water resource management can play a very important role in protecting biodiversity. For this purpose, rainwater harvesting can 
play an important role for existing plants, animals, and other microbes. As the country receives ample rainfall it can be collected which could address water crises problem and ultimately contribute to biodiversity conservation.

Local community rears local livestock such as cows, chicken, duck, goat, and other species during monsoon as the water is available but they can't do this during the dry season as the water becomes scarce. People do not get local livestock in the market during the dry season as local people do not rear it in that season. They have to visit another market or place to get the local livestock. The meat of local livestock is tastier than other livestock so that people are always looking for those livestock particularly for the special program such as the wedding, birthday, the celebration of New Year, and other festivals. Even people look for local livestock when their relative visits them. As rainwater harvesting increase in access to water for the family so that we can say that it also contributes to local biodiversity.

\subsubsection{Sustainability}

Sustainability is the process to maintain balance in an environment where utilize the resource in such a way that does not harm the environment. Moreover, sustainability is the avoidance of the depletion of natural resources in pursuit of maintains ecological balance. Rainwater harvesting can contribute to sustainability in two aspects such as improve water supply and reduce rainwater runoff. These two lead to other aspect which shows in figure 4:

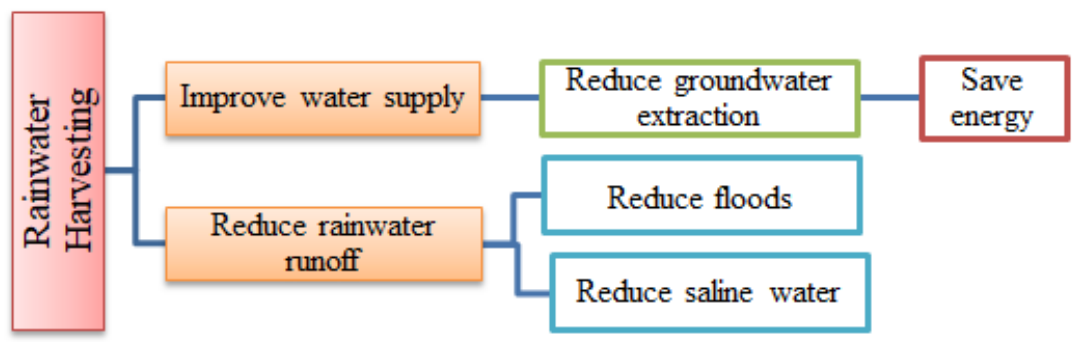

Figure 4: Contribution of rainwater harvesting on sustainability

The study already found that rainwater harvesting increases water supply in the study site that contributes to sustainability directly and indirectly. In the study site, the main source of water is groundwater, river water, and rainwater (Islam, 2017). River water is only useable only in some period of rainy season because rainwater can reduce the intensity of salinity so that people can use river water. As groundwater is one of the main sources of water people are heavily reliant on this source. This dependence leads overexploitation of the source. For instance, groundwater level in Dhaka city is lowering by 1 meter every year (Sengupta et al. 2012) due to over-extraction and it can threaten the sustainability of aquifer. People use rainwater and fulfill their demand through rainwater harvesting rather than groundwater that can reduce the volume of water extraction from the ground source. Moreover, rainwater harvesting does not need energy but groundwater extraction with water pumps needs energy (Abdullah and Rahman, 2015). In this context, rainwater harvesting can save energy. In the current world, energy production is one of the most 
responsible factors for global warming that ultimately lead to climate change. The climate change impact is the most prominent constrains for achieving sustainable development goals (SDG). Here it is assumable that rainwater harvesting contributes to sustainable development through improving water supply that leads to the reduction in groundwater extraction and energy saving. It is notable to mention that SDG 6 is about to access to water so that rainwater harvesting contributes to this goal directly.

Reduce rainwater runoff is another aspect in which rainwater harvesting can contribute in terms of sustainability. It can reduce the volume of rainwater runoff that leads to reducing the volume of saline water as the entire water source (e.g. river, groundwater, pond, canal etc.) near to the study site is polluted with saline water. If rainwater is runoff then it would increase the volume of saline water in those sources and will increase the volume of water in those sources that can lead to local floods. For instance, in 2016, heavy rainfall caused floods where 3.7 million people were affected in nineteen districts. The study site was one of the worst affected areas for this flood.

\subsubsection{Resilience}

Climate change effect increases the extreme events such as sea level rise, floods, droughts, storm surges, cyclone, and salinity intrusion and these climate-induced events greatly facilitate the water crises problem in the coastal region. Moreover, climate change impact increases the intensity and frequency of rainfall that also creates the opportunity for using it for resilience purpose. Resilience is the capacity to absorb the disturbance and retain the same structure (Walker et al. 2004). The research has already found and mentioned in the previous section that rainwater harvesting increases water supply. For this reason, it is mentionable that rainwater harvesting helps to use rainwater for resilience purposes by increasing access to water in the water crises period. It is not only increasing access to water but also creating the opportunity for business development that can also contribute to an increase in resilience to climate change impact. For instance, people buy pond water from the local water trader during the dry season. Water trader collects water from the large pond ${ }^{3}$ and supplies to the local people. They have been doing this business for a long time. Most of the time they can't fulfill water supply demand. Moreover, rainwater has higher quality and demand than pond water but they don't have enough storage capacity and technical capacity to keep it for a long time for the business purpose. If the water trader, as well as rainwater harvester, has the financial and technical capacity they could exploit the opportunity ${ }^{4}$ created by climate change and build resiliency against water crises problem arise from climate change impact, water governance and management problem, and other anthropological interventions.

\section{Concluding Remark}

The SDGs 6 are highly unlikely to be met without proper management of rainwater. Failure to sustainable management of rainwater it can bring devastating effect to society and environment with facilitating floods, water logging, and soil erosion

\footnotetext{
3 Where the water is fresh and not polluted with saline

4 The intensity and frequency of rainfall will increase due to climate change impact
} 
particularly in rain intensive country like Bangladesh.

Sustainable rainwater management is a daunting challenge. It is not only for Bangladesh but also for other countries that have been receiving ample rainfall. There is a big difference between Bangladesh and other countries, is the degree and extent of climate change impact face by Bangladesh as the country is one of the most vulnerable countries to climate change effect. It is enviable that local people are creative in addressing their problem. Moreover, this paper focuses on the community approach in managing rainwater and addressing their water crises problem without harming the environment. The study found that the practice is a sustainable approach to manage rainwater regarding biodiversity conservation, resiliency, sustainability, equitable access to water, and social acceptance. Unfortunately, the people still need government assistance in terms of policy, either finance or rainwater harvesting materials, and training for a more effective and sustainable application of rainwater harvesting for effective management of rainwater.

As coastal people are facing water crises problems particularly in the dry season so that there is a possibility of overharvesting of rainwater in addressing the crises. Harvesting policy can reduce overharvesting possibility of rainwater. This can contribute to sustainable development as overharvesting might hamper natural ecological flow. However, financial or rainwater harvesting materials help can enable the poor people to build rainwater harvesting infrastructure that can make them able to store enough rainwater for the whole year. It might address their water crises problem and will bring socioeconomic benefit to them.

Sustainable development approach is needed to manage rainwater over the long term to overcome the challenges faced by this community practice. It is an interconnected nature of challenges, addressing them is complex and difficult which needs planned management strategies. The initiative should be taken to address these problems so that the community's rainwater management practice can ensure sustainability in managing the rainwater.

The findings have formed the basis for further study in finding the sustainable approach for managing the rainwater in Bangladesh. It is not a conclusive study. In order to move towards a conclusive decision for managing rainwater, more ethnographic and empirical studies are required.

\section{References}

Abdullah, H.M., and Rahman, M.M (2015). Initiating rain water harvest technology for climate change induced drought resilient agriculture: scope and challenges in Bangladesh, JAEID, 109(2):189-208, DOI:10.12895/jaeid.20153.334

Allan, R.P., and Soden, B.J. (2008). Atmospheric Warming and the Amplification of Precipitation Extremes. Science, 321(5895): 1481-1484.

Alexander, L.V., Zhang, X., Peterson, T.C., Caesar, J., Gleason, B., Klein Tank, A.M.G., Haylock, M., Collins, D., Trewin, B., Rahimzadeh, F., Tagipour, A., Rupa Kumar, K., Revadekar, J., Griffiths, G., Vincent, L., Stephenson, D.B., Burn, J., Aguilar, E., Brunet, M., Taylor, M., New, M., Zhai, Rusticucci, M., and Vazquez-Aguirre, J.L. (2006). Global observed changes in daily climate extremes of temperature and precipitation. Journal of Geophysical Research, 111 (5): 1-22.

Anderson, I.M. and Burton, M. (2009). Best Practices and Guidelines for Water Harvesting and Community Based (Small Scale) Irrigation in the Nile Basin. Water Harvesting 
Report. Part I - Best Practices in Water Harvesting. Part II - Guidelines for the implementation of best practices in Water Harvesting. Appendix A: List of Reference Material. Kent, Nile Basin Initiative. Efficient Water Use for Agricultural Production Project (EWUAP).

Briffa, K.R., van der Schrier, G., and Jones, P.D. (2009). Wet and dry summers in Europe since 1750: evidence of increasing drought. International Journal of Climatology 29(13): 1894-1905.

Chambers, R. (1994). The Origins and Practice of Participatory Rural Appraisal. World Development, 22(7): 953-969

Falkenmark, M., Fox, P., Persson, G. and J. Rockström. 2001. Water Harvesting for Upgrading of Rainfed Agriculture: Problem Analysis and Research Needs. Stockholm

International Water Institute (SIWI) Report 11, Stockholm.

Goswami, B.N., Venugopal, V., Sangupta, D., Madhusoodanan, M.S., and Prince, K.X. (2006). Increasing trend of extreme rain events over India in a warming environment. Science, 314(5804): 1442-1445

Huq, N., Huge, J., Boon, E., and Gain, A.K. (2015). Climate Change Impacts in Agricultural Communities in Rural Areas of Coastal Bangladesh: A Tale of Many Stories. Sustainability: Open Access, 7:8437-8460, doi: $10.3390 /$ su7078437

Islam, M.M., Chou, F.N.F., Kabir, M.R., and Liaw, C.H. (2010). Rainwater: A Potential Alternative Source for Scarce Safe Drinking and Arsenic Contaminated Water in Bangladesh. Water Resources Management, 24:3987-4008, DOI:10.1007/s11269-010-9643-7

Ismail, H. (2016). Climate Change, Food and Water Security in Bangladesh. Future Directions international, Strategic Analysis Paper

Liniger, H., Mekdaschi Studer, R., Hauert, C. and Gurtner, M.(2011). Sustainable Land Management in Practice: Guidelines and Best Practices for Sub-Saharan Africa. Terr Africa, World Overview of Conservation Approaches and Technologies (WOCAT) and Food and Agriculture Organization of the United Nations (FAO)

McGranahan, G., BALK, D., and Anderson, B. (2007). The rising tide: Assessing the risk of climate change and human settlements in low elevation coastal zones. Environ. Urban, 19: 17-37

Ngigi, S. N. (2003). Rainwater Harvesting for Improved Food Security: Promising Technologies in the Greater Horn of Africa. Greater Horn of Africa Rainwater Partnership

(GHARP) and Kenya Rainwater Association (KRA), Nairobi, Kenya

Oweis, T.Y., Prinz, D. and Hachum, A.Y. (2012). Water Harvesting for Agriculture in the Dry Area. ICARDA, CRC Press/ Balkema, Leiden, the Netherlands

Schmidli, .J, and Frei, C. (2005). Trends of heavy precipitation and wet and dry spells in Switzerland during the 20th century. International Journal of Climatology 25(6): 753-771.

Sengupta, S., Kang, A., and Jcob, N (2012). Water Wealth A Briefing Paper on the state of Groundwater Management in Bangladesh, Retrieved from http://www.cseindia.org/userfiles/groundwater management bangladesh.pdf

Shahid S. (2008). Spatial and temporal characteristics of droughts in the western part of Bangladesh. Hydrological Processes 22(13): 2235-2247.

(2010). Rainfall variability and the trends of wet and dry periods in Bangladesh. International Journal of Climatology, Wiley Online Library, 30:2299-2313, DOI: 10.1002/joc.2053

Shahid, S., and Behrawan, H. (2008). Drought risk assessment in the western part of Bangladesh. Natural Hazards 46(3): 391-413.

Studer, R.M., and Liniger, H. (2013). Water Harvesting Guidelines to Good Practice. Centre for Development and Environment (CDE), Bern; Rainwater Harvesting Implementation Network (RAIN), Amsterdam; MetaMeta, Wageningen; The International Fund for Agricultural Development (IFAD), Rome.

Walker, B., Holling, C.S., Carpenter, S.R., and Kinzig, A. 2004. Resilience, Adaptability and Transformability in Socioecological Systems. Ecology and Society, 9(2)

Wasimi, S.A. (2009). Climate Change Trends in Bangladesh. Proceedings of 2nd International Conference on Water and Flood Management, 8-10 March 2009, Dhaka, Bangladesh, 1:203-210

Worm, J. and van Hattum, T.(2006). Rainwater harvesting for domestic use. AGROMIS A and CTA / RAIN (Rainwater Harvesting Implementation Network). Wageningen, The Netherlands

Zhang, Q., Xu C-Y, and Zhang, Z. (2009). Observed changes of drought/wetness episodes in the Pearl River basin, China, using the standardized precipitation index and aridity index. Theoretical and Applied Climatology 98(1-2): 89-99. 